\title{
Preliminary numerical study on seismic response of ordinary long-span suspension bridges crossing active faults
}

\author{
Hongyu Jia ${ }^{{ }^{*}}$ (D), Kang Jia ${ }^{1}$, Caizhi Sun ${ }^{2}$, Yanqiang $\mathrm{Li}^{1}$, Chao $_{\text {Zhang }}{ }^{3}$ and Shixiong Zheng ${ }^{1 *}$
}

\author{
* Correspondence: Hongyu1016@ \\ swjtu.edu.cn; zhengsx@home.swjtu. \\ edu.cn \\ ${ }^{1}$ Southwest Jiaotong University, \\ Chengdu 610000, China \\ Full list of author information is \\ available at the end of the article
}

\begin{abstract}
The objective of this paper is to expediently expose the seismic performance pertinent to demand and capacity of general long-span suspension bridges crossing active faults. Firstly three dimensional finite element model of the ordinary long-span suspension bridge is established based on the powerful and attractive finite element software ANSYS. Secondly a series of appropriate fault ground motions with different target final permanent displacements (Tectonic displacements or ground offset) in the direction perpendicular to the fault plane are assumed and applied to the employed long-span suspension bridge. And then the Newmark method is utilized to solve the equation of motion of the long-span suspension bridge structure subjected to fault ground motions in the elastic range. Finally some important conclusions are drawn that the final permanent displacements in the direction perpendicular to the fault plane has significant influence on the seismic responses and demands of general long-span suspension bridges crossing active faults. And the resultant conclusions deliver explicitly and directly specifications and guidelines for seismic design of ordinary long-span suspension bridges across fault-rupture zones.

Keywords: Ordinary long-span suspension bridge, Fault-rupture zone, Final permanent displacement, Seismic performance, Seismic response
\end{abstract}

\section{Introduction}

Highways and railways in China have been extended fully and rapidly to remote areas due to the promotion of transportation power strategy (Jia et al. 2013). With the rapid development of the highway and railway network, the seismic design of bridges located in various site conditions (e.g., near-fault distinct and fault-rupture zone) constantly encounters many challenges (Jia et al. 2018; Yang and Mavroeidis 2018; Garini et al. 2017). Especially the construction of bridges across active faults which has been prohibited or avoided in the code for seismic design of bridges. However it is practically impossible to avoid the construction of bridges crossing active faults in the Sichuan Tibet railway route with national strategic significance (Hongyu et al. 2020).

(c) The Author(s). 2021 Open Access This article is licensed under a Creative Commons Attribution 4.0 International License, which permits use, sharing, adaptation, distribution and reproduction in any medium or format, as long as you give appropriate credit to the original author(s) and the source, provide a link to the Creative Commons licence, and indicate if changes were made. The images or other third party material in this article are included in the article's Creative Commons licence, unless indicated otherwise in a credit line to the material. If material is not included in the article's Creative Commons licence and your intended use is not permitted by statutory regulation or exceeds the permitted use, you will need to obtain permission directly from the copyright holder. To view a copy of this licence, visit http://creativecommons.org/licenses/by/4.0/. 
As known the internal force and displacement responses of bridges crossing fault-rupture zones are governed not only by the vibration of ground surface on both sides of the fault plane but also by the fault-rupture displacement (Yang et al. 2020; Lin et al. 2020a, b) The fault-rupture permanent displacement varying from tens of centimeters to several meters is significantly difference between ground motions at two sides of fault plane and others (Goel et al. 2014; Goel and Chopra 2009; Goel and Chopra 2008). Thus some issues and challenges should be handled in the aspect of bridge seismic design such as how to choose a suitable bridge type to span active faults with permanent ground rupture displacements ranging from tens of centimeters to several meters? and how to improve the capacity of existing bridge types (simply supported beam, continuous beam, arch bridge and cablesupported bridges) to span large ground surface rupture placements? Commonly bridge design engineers adopt the short span simply supported beam bridge to span active fault for minimizing the cost of bridge collapse once the fault rupture displacement induced by earthquakes (Hui et al. 2018; Hui et al. 2015). Although this approach can mitigate the loss from damages of simply supported beam bridge it will result in traffic disruption, difficulty to repair, and safety accident of railway operation. Additionally the cable-supported bridges which belongs to flexible system bridge type has good adaptability to large fault rupture displacement. The suspension bridge of flexible system bridges has the largest spanning capacity and is a reasonable choice for crossing active faults as well. However few investigations on the dynamical responses of long-span suspension bridges crossing active faults are conducted in recent years (Yang and Mavroeidis 2018; Hongyu et al. 2020) Hence the intensive appealing for long-span suspension bridges on its spanning fault capacity is raised in bridge engineering field to estimate the spanning fault capability.

Although the partial studies are available in the literatures on the bridge structures crossing active faults, to the best knowledge of the authors, it is insufficient practically to cross large ground offset for capacity of existing bridge types (Lin et al. 2018; Zhou et al. 2014; Lin et al. 2020a, b). The related attempts on mechanism of fault earthquake and response characteristics, failure mode and mechanism of long-span suspension bridges under fault earthquakes need to be studied to upgrade spanning fault ability of long-span suspension bridges. Compared to this type of bridge situated in non-fault regions it is more vulnerable to bridges resisting across-fault earthquake ground motions. The main reason that the bridges across active fault damaged and even collapsed in earthquakes is because the surface fault rupture offset between two sides of fault plane. Since the first event of bridge damage across fault was observed in 1906 San Francisco earthquake, more than 30 highway and railway bridges crossing ground surface rupture faults have been seriously damaged or even collapsed with great economic losses and casualties in the 1999 Turkey Earthquake, Taiwan Chi-Chi earthquake and 2008 Wenchuan earthquake (Yang and Mavroeidis 2018). Therefore many evasive methods (e.g., effective avoidance distance) have been proposed to avoid the risk such as building bridges on faults (Jia et al. 2019). Despite these evasive methods has a certain effect to reduce the vulnerability of bridges in near fault zones, bridges across fault are unstoppable with the construction of Sichuan Tibet railway line in China. Consequently how to reduce the seismic damage of the bridges crossing active fault is the most important problems to be solved presently. 
Moreover some existing efforts have investigated experimentally and numerically the seismic responses of bridge structures crossing fault-rupture zones (Zhang et al. 2020; Yi et al. 2019). Gloyd et al. proposed a simplified method to estimate the seismic demand of ordinary bridges traversing active faults (Gloyd et al. 2002). Anastasopoulos et al. presented two-step analysis and design method for bridges supported on two sides of fault plane (Anastasopoulos et al. 2008; Fadaee et al. 2013). Der Kiureghian and Neuenhofer estimated the seismic demand of a 4-span curved bridge by using multipoint response spectrum method (Der Kiureghian and Neuenhofer 1992). Meanwhile from the scaled shaking table test aspect Huang et al. studied the relationship between surface rupture and bridge damage mode caused by discontinuous reverse faults through a 1/250 scale 2-span bridge model (Wong et al. 2010). Saiidi et al. performed experimentally the fracture failure of a 1/ 4 scale two span reinforced concrete bridge (Saiidi et al. 2014). Hui Yingxin et al. carried out a series of researches on these issues of seismic input, model establishment, and seismic response of crossing fault bridges (Hui et al. 2018). Zhang Fan et al. analyzed the influence of intersection angle between fault and bridge and ground rupture permanent displacement on seismic performance of simply supported beam bridges (Zhang et al. 2020). Following the above extensive analyses and reviews, there are few studies on cable-supported bridge structures crossing active fault. The ground vibration and ground surface rupture offset controlling respectively relative dynamic term and quasi static term in the equation of motion of structures are responsible for seismic performance of cable-supported bridge structures crossing active fault. Nevertheless the cable-supported bridge structures are insensitive to the quasi static term, namely the ground surface rupture offset has less effect on seismic responses of cable-supported bridge structures traversing active faults. As a superior bridge type selected to span active faults it is excessively imperative and essential to study the seismic performance of cable-supported bridge crossing active fault.

To provide in-depth insight into seismic performance of cable-supported bridge crossing active fault the objective of this study is to preliminarily study the spanning capability of ordinary long-span suspension bridges crossing active faults. Based on original ground motion records in 1999 Chi-Chi earthquake, the assumed seismic ground motions applied to the employed ordinary long-span suspension bridge are adjusted firstly with different target final permanent displacements. And displacement-based seismic excitation mode in seismic response analysis is utilized herein to model the mechanism to complicated fault ground motions exerted to structures. Furthermore some limited explanation in this paper are given herein. For example all most analyses are controlled in elastic range except for geometric nonlinearity of main cable. The ordinary long-span suspension bridge is defined as this kind bridge specifically designed not to traverse faults. Besides so-called preliminary numerical study of ordinary longspan suspension bridge crossing fault considers only longitudinal seismic excitations for capability estimation of adapting to horizontal permanent ground rupture displacement and the vertical ground motions and the pile-soil interaction will be ignored in this paper.

\section{Principle of displacement-based seismic ground motion excitation}

Since the permanent surface rupture displacement is one of the fundamental characteristics of fault earthquakes and primarily govern the quasi static displacement term in 
equation of motion it is extremely advisable and reasonable to decouple the absolute displacement into quasi static and dynamic terms (Zhang et al. 2014; Qu and Goel 2015; Goel et al. 2014). Hence the equation of motion of suspension bridges subjected to fault seismic excitations is written as

$$
\left[\begin{array}{ll}
\mathbf{M}_{\mathrm{aa}} & \mathbf{M}_{\mathrm{ab}} \\
\mathbf{M}_{\mathrm{ba}} & \mathbf{M}_{\mathrm{bb}}
\end{array}\right]\left[\begin{array}{c}
\ddot{\mathbf{u}}_{\mathrm{a}} \\
\ddot{\mathbf{u}}_{\mathrm{b}}
\end{array}\right]+\left[\begin{array}{ll}
\mathbf{C}_{\mathrm{aa}} & \mathbf{C}_{\mathrm{ab}} \\
\mathbf{C}_{\mathrm{ba}} & \mathbf{C}_{\mathrm{bb}}
\end{array}\right]\left[\begin{array}{c}
\dot{\mathbf{u}}_{\mathrm{a}} \\
\dot{\mathbf{u}}_{\mathrm{b}}
\end{array}\right]+\left[\begin{array}{ll}
\mathbf{K}_{\mathrm{aa}} & \mathbf{K}_{\mathrm{ab}} \\
\mathbf{K}_{\mathrm{ba}} & \mathbf{K}_{\mathrm{bb}}
\end{array}\right]\left[\begin{array}{l}
\mathbf{u}_{\mathrm{a}} \\
\mathbf{u}_{\mathrm{b}}
\end{array}\right]=\left[\begin{array}{l}
\mathbf{R}_{\mathrm{a}} \\
\mathbf{R}_{\mathrm{b}}
\end{array}\right]
$$

where $\ddot{\mathbf{u}}_{\mathrm{a}}, \dot{\mathbf{u}}_{\mathrm{a}}$, and $\mathbf{u}_{\mathrm{a}}$ represent acceleration, velocity, and displacement vectors of nonsupported structural nodes respectively; $\ddot{\mathbf{u}}_{\mathrm{b}}, \dot{\mathbf{u}}_{\mathrm{b}}$, and $\mathbf{u}_{\mathrm{b}}$ indicate acceleration, velocity, and displacement vectors of supported structural nodes (namely action point of earthquake on structure, generally e.g., bottom ends of pier and tower); $\mathbf{M}, \mathbf{C}$, and $\mathbf{K}$ denote mass, damping, and stiffness matrices of suspension bridges respectively, the subscripts of aa, bb, and $\mathrm{ab}(\mathrm{ba})$ represent nodal degrees of freedom pertinent to supported structure, non-supported structure, and mutual coupling terms; $\mathbf{R}_{\mathrm{a}}$ expresses force excitation vector on nodes of non-supported structure components e.g., vehicle load, wind load, and pedestrian load vectors, etc. And let $\mathbf{R}_{\mathrm{a}}=0$, because above-mentioned loads aren't considered herein; $\mathbf{R}_{\mathrm{b}}$ is seismic excitation vector at supported structural nodes.

Expanding the first term of Eq. (1), the dynamic equilibrium equation of nonsupported nodes can be obtained

$$
\mathbf{M}_{\mathrm{a} a} \ddot{\mathbf{u}}_{\mathrm{a}}+\mathbf{M}_{\mathrm{ab}} \ddot{\mathbf{u}}_{\mathrm{b}}+\mathbf{C}_{\mathrm{a} a} \dot{\mathbf{u}}_{\mathrm{a}}+\mathbf{C}_{\mathrm{ab}} \dot{\mathbf{u}}_{\mathrm{b}}+\mathbf{K}_{\mathrm{a} a} \mathbf{u}_{\mathrm{a}}+\mathbf{K}_{\mathrm{ab}} \mathbf{u}_{\mathrm{b}}=\mathbf{0}
$$

Because the lumped mass method is adopted hereon, one has $\mathbf{M}_{\mathrm{ab}}=\mathbf{0}$.

Further the Eq. (2) can be simplified as follows

$$
\mathbf{M}_{\mathrm{aa}} \ddot{\mathbf{u}}_{\mathrm{a}}+\mathbf{C}_{\mathrm{aa}} \dot{\mathbf{u}}_{\mathrm{a}}+\mathbf{K}_{\mathrm{aa}} \mathbf{u}_{\mathrm{a}}=-\mathbf{K}_{\mathrm{ab}} \mathbf{u}_{\mathrm{b}}-\mathbf{C}_{\mathrm{ab}} \dot{\mathbf{u}}_{\mathrm{b}}
$$

The Eq. (3) is the dynamic equation of displacement-based input mode.

\section{Assumption of fault ground motion input}

The measured ground motion records (TCU049 and TCU052) less than $5 \mathrm{~km}$ away from fault plane in 1999 Chi-Chi earthquake are taken as the seismic input to longspan suspension bridge crossing active fault. The seismic arrays of TCU049 and the TCU052 are located on the footwall and hanging wall respectively shown in Fig. 1. Thus it is reasonable to consider the measured ground motion records (TCU049 and TCU052) as the seismic input in the seismic analysis of long-span suspension bridges crossing active faults. Moreover the velocity and displacement traces of measured ground motion records (TCU049 and TCU052) with baseline drift problems originated mainly from low-frequency instrument noise, low-frequency background noise, the small initial values for acceleration and velocity, manipulation errors, hysteresis of the transducers, ground rotation and tilting are corrected by using a baseline correction method (Lin et al. 2018). The resultant corrected ground motion records including displacement record in Fig. 2 are validated in accordance with GPS-measured coseismic displacements (G103 and M324 respectively corresponding to TCU049 and TCU052). The original acceleration records in TCU049 and TCU052 arrays are given in Fig. 3a and the corresponding corrected velocity record are also shown in Fig. 3b. After baseline correction of ground motion the velocity of 0 at the end of earthquake implies the baseline drift has been eliminated. The displacement time history with permanent fault 


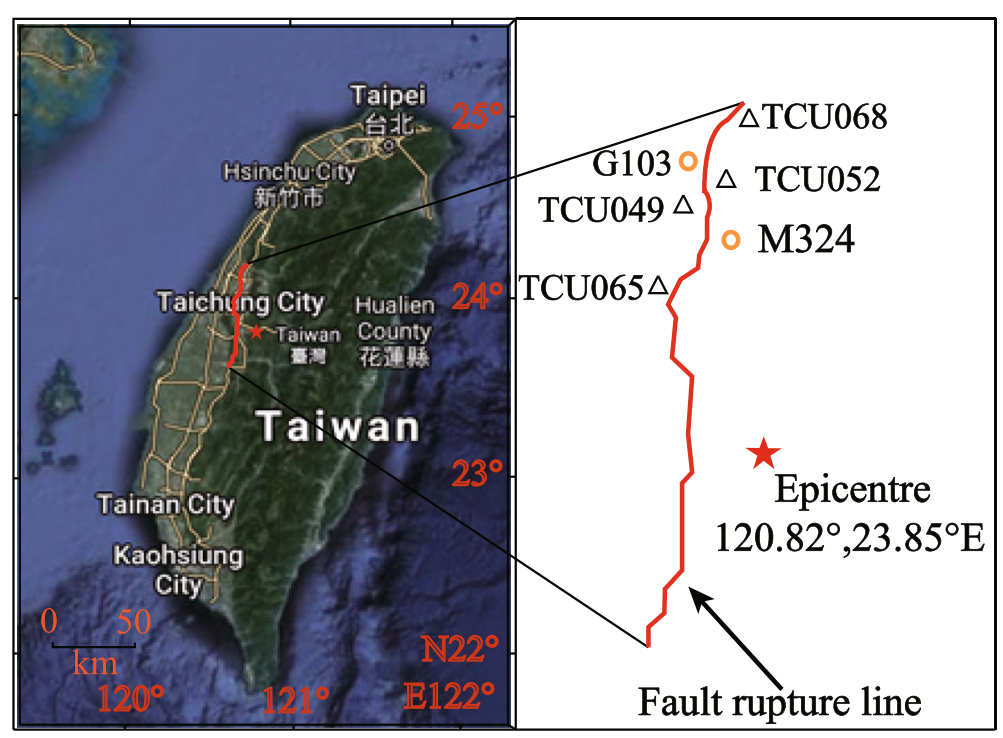

Fig. 1 Arrangement of seismic array and GPS station in Chi-Chi earthquake

rupture offsets will be obtained by the integral of corrected velocity time history. For spanning ability estimation of long-span suspension bridges a serial of target ground motions with different final fault rupture permanent displacements should be considered, consequently the final fault rupture permanent displacements of $0,0.2,0.5,0.8$, and $1.0 \mathrm{~m}$ are examined in the spanning capability assessment of ordinary long-span suspension bridges crossing active faults (Fig. 4).

\section{Numerical analysis}

\subsection{Ordinary long-span suspension bridge and finite element model}

To investigate the spanning capability of ordinary long-span suspension bridge without specialized design for crossing active faults a long-span suspension bridge located in the western Guizhou province of China is employed herein. The primary structure of long-span suspension bridge with layout of $136 m+538 m+136 m$ is composed of main tower, steel truss girder, and main cable. This long-span suspension bridge is situated

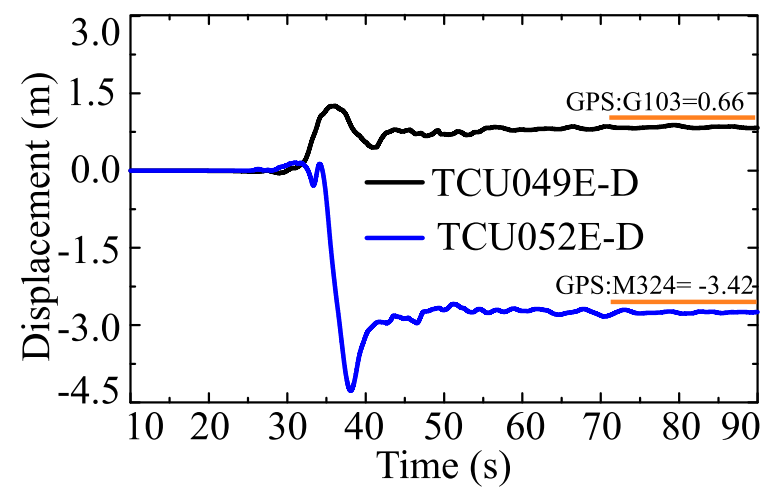

Fig. 2 Corrected ground motion displacement records 


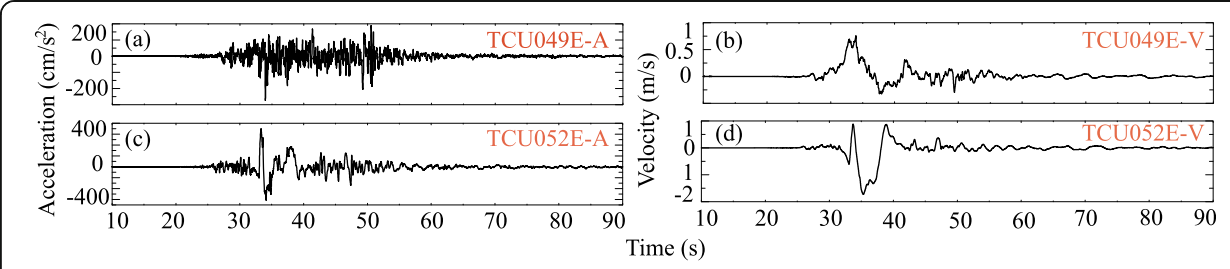

Fig. 3 Original acceleration record and corrected velocity record in TCU049 and TCU052 arrays

on a V-shape gully region with the riverbed length approximate $120 \mathrm{~m}$. The main towers with the heights of $137 \mathrm{~m}$ and $62.5 \mathrm{~m}$ in $1 \#$ and 2\# towers respectively adopts reinforced concrete portal frame structure with bridge width of $27 \mathrm{~m}$. The detailed information of seismic excitations and ordinary long-span suspension bridge is given in the Fig. 5.

A 3-D finite element model of the ordinary long-span suspension bridge is built using a general finite element platform ANSYS (Fig. 6). The Beam189 element is used to model main girders and towers. The Mass21 element is adopted to simulate the dead load that are attached to main girders. The Shell163 element is utilized to model steel deck. The Combin14 element is employed to simulate bearing and linear viscous damper installed between tower and girder. The material parameter information in numerical analysis of structural components is given in Table 1. For taking into account the weight of component connection point the densities of concrete and steel materials are amplified by $10 \%$ roughly and conservatively (Namely multiply by a factor of 1.1) (Yang and Mavroeidis 2018; Yang et al. 2020). Owing to neglecting the pile-soil interaction the end of pile is fixed except the displacement-based ground motion is imposed respectively to this partial structure lied on the hanging wall or footwall. The damping ratios of all the modes of interest are assumed to be 0.05 .

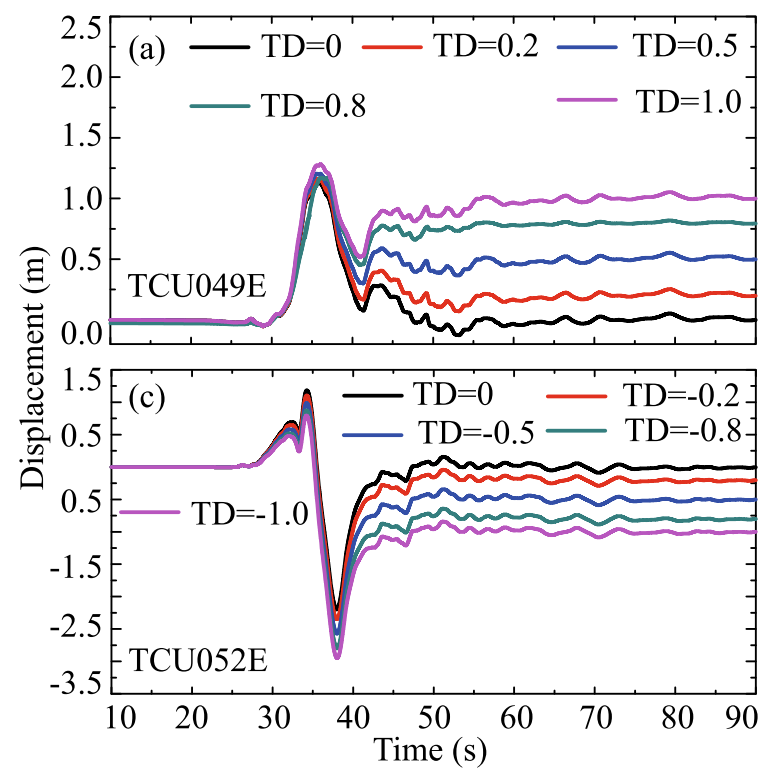

Fig. 4 Final fault rupture permanent target displacements (TD: target displacement) 


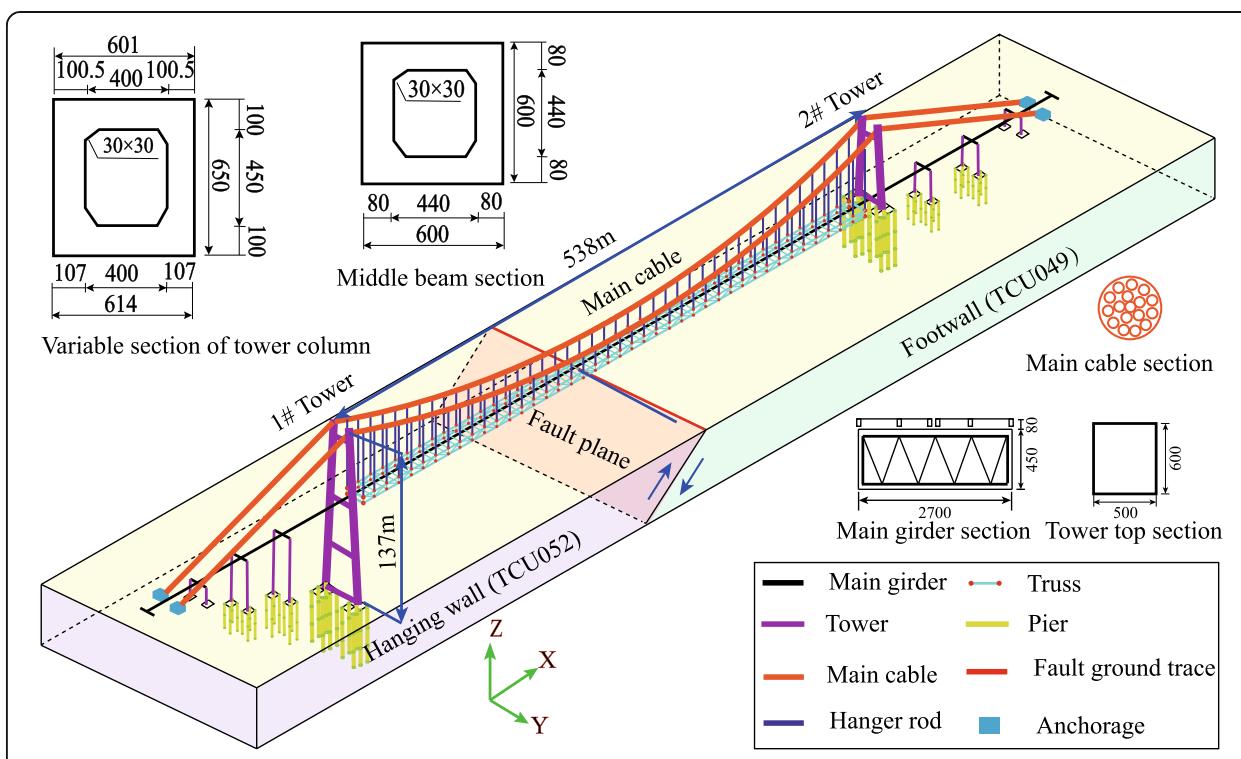

Fig. 5 Schematic view of fault seismic ground motions and long-span suspension bridge structure

\subsection{Response analysis and discussion}

To estimate the spanning fault capability of ordinary long-span suspension subjected to ground motions with different target permanent rupture displacements the responses of interest are examined e.g., displacement responses of tower top and girder and internal force responses of tower bottom and main cable and so on.

\subsubsection{Displacement response}

In this section the displacement responses of interest in seismic analysis of ordinary long-span suspension bridges crossing active faults are examined e.g., longitudinal displacements of 1\# tower top and 2\# tower top, vertical displacement of mid-span girder, and longitudinal displacements of girder ends close to1\# tower and 2\# tower respectively. The peak values of displacement response of employed long-span suspension

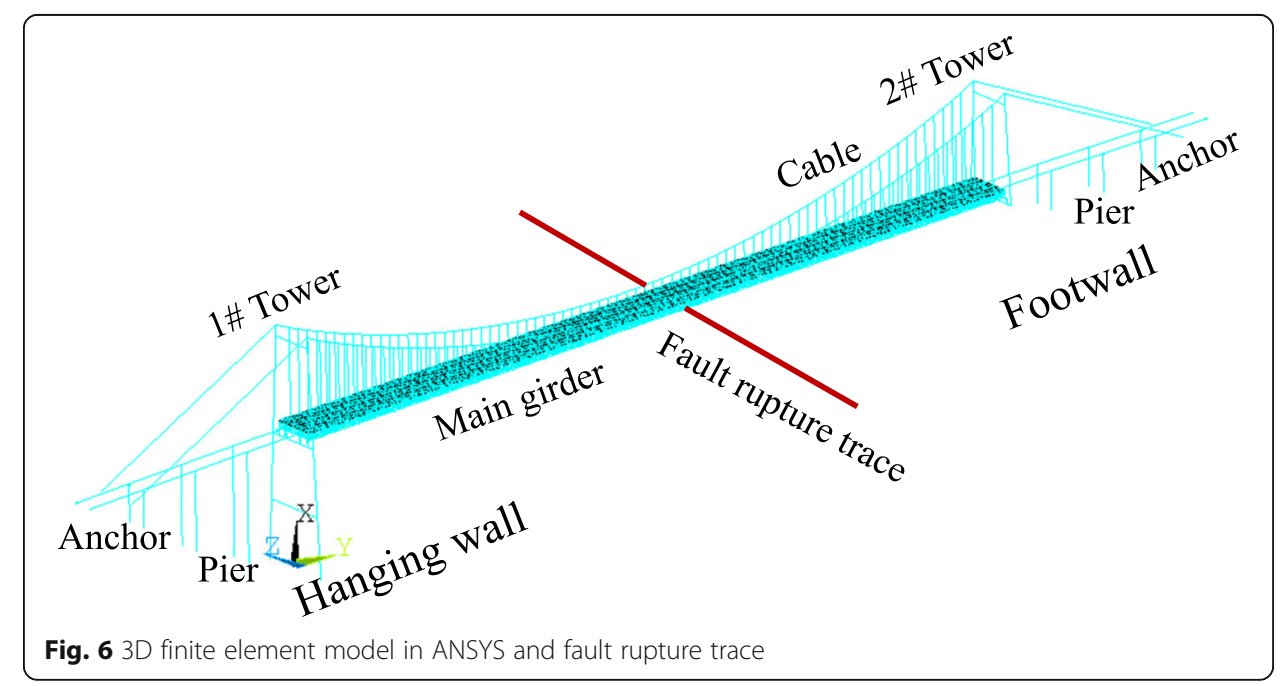


Table 1 Material information

\begin{tabular}{llll}
\hline Material & Elastic modulus & Poisson's ratio & Density $\left(\mathbf{K g} / \mathbf{m}^{\mathbf{3}}\right)$ \\
\hline Concrete & $3.5 \times 10^{10}$ & 0.2 & 2887.5 \\
Steel & $2.1 \times 10^{11}$ & 0.3 & 8242.3 \\
Cable & $2.0 \times 10^{11}$ & 0.17 & 8400 \\
\hline
\end{tabular}

bridge subjected to faulting ground motions with different target ground surface rupture permanent displacements are given in Table 2. As seen from Table 2 the longitudinal displacements of $1 \#$ tower top are extremely larger than ones of $2 \#$ tower top of ordinary long-span suspension bridges crossing active faults owing to hanging wall effect which is due mainly to the proximity of much of the fault to hanging wall sites. The hanging wall effect is one of the most important characteristics of near fault ground motions, especially for reverse faults. Typically the hanging wall is closer to the epicenter, and multiple reflections occur between the ground surface and the fault plane. Namely the hanging wall effect is due mainly to the proximity of much of the fault to hanging wall sites. These result in more intense ground motions on the hanging wall site compared with the footwall site. Hence the longitudinal displacements of $1 \#$ tower top with increase of TDs have obviously dynamic responses. Meanwhile for the fault ground motion inputs the measured ground motion records in TCU052 array located in hanging wall have larger amplitudes of acceleration, velocity, and displacement in Figs. 2, 3 and 4 compared to ones from TCU049 array in footwall. The main girder may be pulled up by main cable and extensive suspenders due to relatively distant movement between $1 \#$ tower and $2 \#$ tower caused by ground permanent dislocations. Thus the vertical displacement response of mid-span girder is used to assess the lifting height of main girder of ordinary long-span suspension bridges under fault ground motions. It seem to be remarkable that main girder is lifted with variation of TDs in ordinary long-span suspension bridges thanks to vertical displacement responses from 5.669 $\mathrm{m}$ to $7.657 \mathrm{~m}$ in Table 2 . It should be noteworthy that only seismic loads and main cable strain of 0.003 are considered herein but not structural gravity. The longitudinal displacement of girder end can reflect the prominent performance of viscous damper installed between tower and girder. As indicated in Table 2 without ground rupture permanent displacement namely $\mathrm{TD}=0$ the longitudinal displacements of girder ends close to 1 \# tower and 2\# tower are the largest ( -2.071 and -2.431 respectively). Nevertheless it is revealed that the ground rupture permanent displacement may induce the longitudinal displacement responses though this seismic analysis of ordinary long-span suspension bridges crossing active faults. More detailed information of responses of employed long-span suspension bridges are given in Fig. 7.

Table 2 Peak value of displacement response under different TDs (Unit: m)

\begin{tabular}{|c|c|c|c|c|c|}
\hline Peak value of displacement response & $\mathrm{TD}=0$ & $\mathrm{TD}=0.2$ & $\mathrm{TD}=0.5$ & $\mathrm{TD}=0.8$ & $\mathrm{TD}=1$ \\
\hline Longitudinal displacement of 1\# tower top & -2.245 & -2.37 & -2.586 & -2.802 & -2.946 \\
\hline Longitudinal displacement of 2\# tower top & 1.075 & 1.084 & 1.113 & 1.144 & 1.160 \\
\hline Vertical displacement of mid-span girder & 5.669 & 6.392 & 6.867 & 7.352 & 7.657 \\
\hline Longitudinal displacement of girder end close to $1 \#$ tower & -2.071 & 1.147 & -1.217 & -1.283 & -1.334 \\
\hline Longitudinal displacement of girder end close to $2 \#$ tower & -2.431 & -1.463 & -1.561 & -1.654 & -1.722 \\
\hline
\end{tabular}




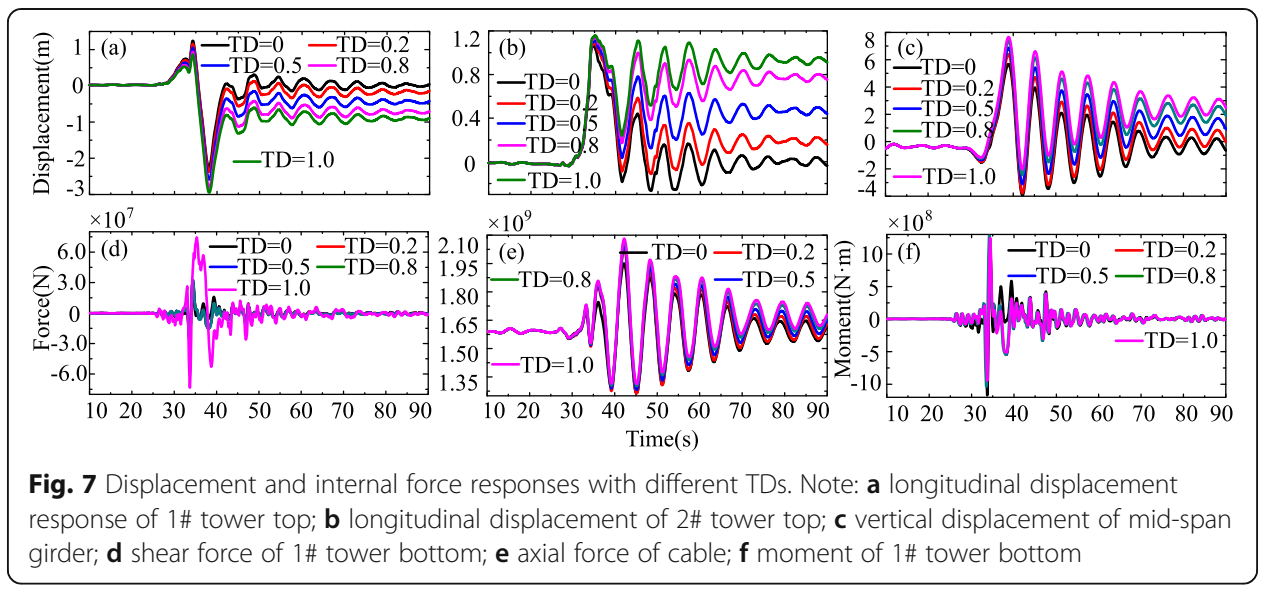

\subsubsection{Internal force response}

The internal force responses (e.g., shear force and moment of tower bottom and axial forces of cable and suspender) of ordinary long-span suspension bridges crossing active faults can represent the dynamic performance which determines whether the structure is plastic or not. Firstly under the most unfavorable axial force of tower the equivalent moment $\left(5.92 \times 10^{8} \mathrm{~N} \cdot \mathrm{m}\right)$ around $\mathrm{Z}$ axis is ascertained based on moment- curvature analysis in the Xtract software. It will be very clear that the moment responses of $1 \#$ tower bottom with variation of TDs have exceeded the equivalent moment $\left(5.92 \times 10^{8}\right.$ $\mathrm{N} \cdot \mathrm{m})$ and have resulted structure component into plastic deformation. In addition the axial force responses of cable and suspender with changes of TDs are also given in Table 3. Practically the employed ordinary long-span suspension bridge doesn't consider the special design to span the active faults and its maximum acceleration of fortification $\left(124.7 \mathrm{~cm} / \mathrm{s}^{2}\right)$ is much smaller than the acceleration (Approximate $400 \mathrm{~cm} / \mathrm{s}^{2}$ ) in Fig. 3. Thus this ordinary long-span suspension bridge has greater dynamic responses herein. And once the ordinary suspension bridge is used to cross the fault, it must be specially designed to upgrade the capability of traversing active faults. It is remarkably noticeable that the internal force and displacement responses of bridges crossing fault-rupture zones are governed not only by the vibration of ground surface on both sides of the fault plane but also by the fault-rupture displacement. The values of TD can more severely dominate final status of bridges crossing fault-rupture zones such as sustained stress and tilt failure compared to pure ground vibration.

\section{Conclusions}

For assessment of seismic performance pertinent to demand and capacity of general long-span suspension bridges crossing active faults 3D finite element model of the ordinary long-span suspension bridge is established based on the powerful and attractive

Table 3 Peak value of internal force response under different TDs

\begin{tabular}{llllll}
\hline Peak value of internal force response & TD = 0 & TD = 0.2 & TD = 0.5 & TD = 0.8 & TD = 1 \\
\hline Shear force of 1\# tower bottom $(\mathrm{N})$ & $-2.98 \times 10^{7}$ & $3.24 \times 10^{7}$ & $3.24 \times 10^{7}$ & $3.24 \times 10^{7}$ & $7.43 \times 10^{7}$ \\
Moment of 1\# tower bottom $(\mathrm{N} \cdot \mathrm{m})$ & $-1.17 \times 10^{9}$ & $1.28 \times 10^{9}$ & $1.28 \times 10^{9}$ & $1.28 \times 10^{9}$ & $1.25 \times 10^{9}$ \\
Axial force of Cable(N) & $1.95 \times 10^{9}$ & $2.03 \times 10^{9}$ & $2.05 \times 10^{9}$ & $2.07 \times 10^{9}$ & $2.08 \times 10^{9}$ \\
Axial force of Suspender $(\mathrm{N})$ & $1.76 \times 10^{9}$ & $1.78 \times 10^{9}$ & $1.78 \times 10^{9}$ & $1.77 \times 10^{9}$ & $1.77 \times 10^{9}$ \\
\hline
\end{tabular}


finite element software ANSYS. And a series of appropriate fault ground motions with different target final permanent displacements (Tectonic displacements or ground offset) in the direction perpendicular to the fault plane are assumed and applied to the employed long-span suspension bridge. The following conclusions can be drawn as:

(1) It is of great necessarity to consider special seismic design for ordinary long-span suspension bridges crossing active faults owing to excessive capacity demand. It will be very clear that the moment responses of tower bottom with variation of TDs have exceeded the equivalent moment $\left(5.92 \times 10^{8} \mathrm{~N} \cdot \mathrm{m}\right)$ and reveals structure component into plastic deformation.

(2) Nonlinearity should be paid enough attention to seismic performance analysis of long-span suspension bridges crossing faults with ground rupture permanent dislocations. The ground rupture permanent displacement is most important reason to result in larger responses of employed long-span suspension bridge.

(3) The peak internal responses of main cable, suspender, and vertical displacement responses of main girder are deemed to be controlling critical components in seismic analysis of long-span suspension bridges crossing active faults.

\section{Acknowledgments}

The research for this paper was supported partially by the Science and Technology Plan of Sichuan Science and Technology Department (No.2019YJ0243, No.2019YFG0460, and No.2020YJ0081), Major Systematic Projects of China Railway Corporation (No.P2018G007), National Science Foundation of China (No.51308465), and Postdoctoral Science Foundation of China (No.2015 M580031). The authors would like to express their sincere gratitude to all the sponsors for the financial support.

\section{Authors' contributions}

JIA Hongyu, JIA Kang, SUN Caizhi, LI Yanqiang, ZHANG Chao, and ZHENG Shixiong collected the information about bridges crossing faults and were major contributors in writing the manuscript. JA Hongyu established the framework of the manuscript and were major contributors in writing the manuscript. All authors read and approved the final manuscript.

\section{Funding}

This research work was jointly supported by the Science and Technology Plan of Sichuan Science and Technology Department (No.2019YJ0243, No.2019YFG0460, and No.2020YJ0081), Major Systematic Projects of China Railway Corporation (No.P2018G007), National Science Foundation of China (No.51308465), and Postdoctoral Science Foundation of China (No.2015 M580031).

\section{Availability of data and materials}

The datasets used and analyzed during the current study are available from the corresponding author on reasonable request.

\section{Competing interests}

The authors declare that they have no competing interests.

\section{Author details}

${ }^{1}$ Southwest Jiaotong University, Chengdu 610000, China. ${ }^{2}$ Sichuan Highway Planning, Survey, Design and Research Institute Ltd, Chengdu 610041, China. ${ }^{3}$ School of Civil Engineering, Fuzhou University, Fuzhou 350108, China.

Received: 24 November 2020 Accepted: 28 January 2021

Published online: 06 April 2021

\section{References}

Anastasopoulos I, Gazetas G, Drosos V et al (2008) Design of bridges against large tectonic deformation. Earthq Eng Eng Vib 7(4):345-368

Fadaee M, Anastasopoulos I, Gazetas G et al (2013) Soil bentonite wall protects foundation from thrust faulting: analyses and experiment. Earthq Eng Eng Vib 12(3):473-486

Garini E, Gazetas G, Anastasopoulos I (2017) Evidence of significant forward rupture directivity aggravated by soil response in an $M(w) 6$ earthquake and the effects on monuments. Earthq Eng Struct D 46(13):2103-2120

Gloyd S, Fares R, Sánchez A, Trinh V (2002) Designing Ordinary Bridges for Ground Fault Rupture, Third National Seismic Conference and Workshop on Bridges and Highways Portland, Oregon 1-12

Goel R, Qu B, Tures J et al (2014) Validation of Fault Rupture-Response Spectrum Analysis Method for Curved Bridges Crossing Strike-Slip Fault Rupture Zones. Journal of Bridge Engineering 19(5):06014002 
Goel RK, Chopra AK (2008) Role of shear keys in seismic behavior of bridges crossing fault-rupture zones. J Bridg Eng 13(4): 398-408

Goel RK, Chopra AK (2009) Nonlinear analysis of ordinary bridges crossing fault-rupture zones. J Bridg Eng 14(3):216-224

Hongyu J, Yang J, Zheng S, Canhui Z, Xiuli D (2020) A review on aseismic bridges crossing fault rupture regions. J Southwest Jiaotong Univ 2(4):20-36

Hui Y, Mao M, Liu H et al (2018) Influence of structural seismic response of bridges crossing active fault. J Jilin Univ Eng Technol Edition 48:1725-1734 (1671-5497(2018)48:6<1725:KDCQLJ>2.0.TX;2-M6);1725-1734

Hui Y, Wang K, Wu G et al (2015) Seismic responses of bridges crossing faults and their best crossing angles. J Vibration Shock 34:6-11, 17 (1000-3835(2015)34:13<6:KDCQLD>2.0.TX;2-413): 6-11, 17

Jia H, Lan X, Zheng S et al (2019) Assessment on required separation length between adjacent bridge segments to avoid pounding. Soil Dyn Earthq Eng 120:398-407

Jia H, Zhang D, Zheng S et al (2013) Local site effects on a high-pier railway bridge under tridirectional spatial excitations: nonstationary stochastic analysis. Soil Dyn Earthq Eng 52:55-69

Jia H, Zhao J, Li X et al (2018) Probabilistic pounding analysis of high-pier continuous rigid frame bridge with actual site conditions. Earthq Struct 15(2):193-202

Der Kiureghian A, Neuenhofer A (1992) Response spectrum method for multi-support seismic excitations. Earthquake Engineering and Structural Dynamics 21(8):713-740

Lin Y, Zong Z, Bi K et al (2020a) Numerical study of the seismic performance and damage mitigation of steel-concrete composite rigid-frame bridge subjected to across-fault ground motions. B Earthq Eng 18(15):6687-6714

Lin Y, Zong Z, Bi K et al (2020b) Experimental and numerical studies of the seismic behavior of a steel-concrete composite rigid-frame bridge subjected to the surface rupture at a thrust fault. Eng Struct 205:110105.1-110105.21

Lin Y, Zong Z, Tian S et al (2018) A new baseline correction method for near-fault strong-motion records based on the target final displacement. Soil Dyn Earthq Eng 114:27-37

Qu B, Goel RK (2015) Fault-Rupture Response Spectrum Analysis of a Four-Span Curved Bridge Crossing Earthquake Fault Rupture Zones, Structures Congress 2015. Portland, Oregon. https://doi.org/10.1061/9780784479117.156

Saiidi MS, Vosooghi A, Choi H, et al (2014) Shake table studies and analysis of a two-span RC bridge model subjected to a fault rupture. J Bridge Eng 19(8):A4014003. https://doi.org/10.1061/(ASCE)BE.1943-5592.0000478

Wong RHC, Zhang QB, Cheung KHT (2010) Geomechanical model testing of surface rupture and bridge damage produced by discontinuous reverse faults. Journal of Sichuan University 5(42):58-67. (In Chinese)

Yang S, Mavroeidis GP (2018) Bridges crossing fault rupture zones: a review J. Soil Dyn Earthq Eng 113:545-571

Yang S, Mavroeidis GP, Ucak A (2020) Analysis of bridge structures crossing strike-slip fault rupture zones: a simple method for generating across-fault seismic ground motions. Earthq Struc 49(13):1281-1307

Yi J, Yang H, Li J (2019) Experimental and numerical study on isolated simply-supported bridges subjected to a fault rupture. Soil Dynamics and Earthquake Engineering 127:105819.1-105819.11. https://doi.org/10.1016/j.soildyn.2019.105819

Zhang D, Jia H, Zheng S et al (2014) A highly efficient and accurate stochastic seismic analysis approach for structures under tridirectional nonstationary multiple excitations. Comput Struct 145:23-35

Zhang F, Li S, Wang J, et al (2020) Effects of fault rupture on seismic responses of fault-crossing simply-supported highway bridges. Engineering Structures 206:110104. https://doi.org/10.1016/j.engstruct.2019.110104

Zhou B, Song T, Wen R et al (2014) Permanent Displacement Identification Analysis in 2011 Mw9.0 Tohoku Earthquake, Japan. AMM 580-583:1533

\section{Publisher's Note}

Springer Nature remains neutral with regard to jurisdictional claims in published maps and institutional affiliations.

\section{Submit your manuscript to a SpringerOpen ${ }^{\circ}$ journal and benefit from:}

- Convenient online submission

- Rigorous peer review

- Open access: articles freely available online

- High visibility within the field

- Retaining the copyright to your article

Submit your next manuscript at $\boldsymbol{\sim}$ springeropen.com 